\title{
Gas Sorption
}

National Cancer Institute

\section{Source}

National Cancer Institute. Gas Sorption. NCI Thesaurus. Code C78875.

A technique where a sample is heated and deg assed to remove contaminants, followed by exposure to doses of an inert gas. The adsorption of the gas is measured and, subsequently, the gas is withdrawn while the desorption is measured. The profile of adsorption and desorption of the gas at various vacuum pressures can be used to determine the surface area of the sample. 